\title{
Fixed point result and applications on a $b$-metric space endowed with an arbitrary binary relation
}

\author{
Wutiphol Sintunavarat ${ }^{1 *}$, Somyot Plubtieng ${ }^{2}$ and Phayap Katchang ${ }^{3 *}$
}

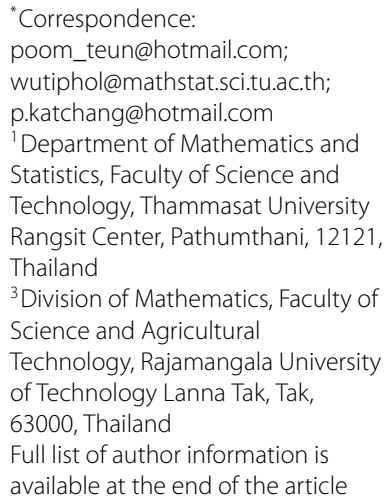

\begin{abstract}
In this paper, we introduce the concept of $q$-set-valued $\alpha$-quasi-contraction mapping and establish the existence of a fixed point theorem for this mapping in $b$-metric spaces. Our results are generalizations and extensions of the result of Aydi et al. (Fixed Point Theory Appl. 2012:88, 2012) and some recent results. We also state some illustrative examples to claim that our results properly generalize some results in the literature. Further, by applying the main results, we investigate a fixed point theorem in a $b$-metric space endowed with an arbitrary binary relation. At the end of this paper, we give open problems for further investigation.
\end{abstract}

MSC: $47 \mathrm{H} 10 ; 54 \mathrm{H} 25$

Keywords: $\alpha$-admissible mapping; binary relation; fixed point; $b$-metric space; q-set-valued $\alpha$-quasi-contraction

\section{Introduction}

Fixed point theory is one of the cornerstones in the development of mathematics since it plays a basic role in applications of many branches of mathematics. The famous Banach contraction principle is one of the most efficient power tools to study in this field since it can be observed easily and comfortably. In 1989, Bakhtin [1] introduced the concept of $b$-metric space and presented the contraction mapping in $b$-metric spaces that is generalization of the Banach contraction principle in metric spaces (see also Czerwik [2]). Subsequently, several researchers studied fixed point theory or the variational principle for single-valued and set-valued mappings in $b$-metric spaces (see [3-9] and references therein).

Recently, Aydi et al. [10] established the $q$-set-valued quasi-contraction mapping which is a generalization of the $q$-set-valued quasi-contraction mapping due to Amini-Harandi [11] in 2011. They also established a fixed point theorem for such a mapping in $b$-metric spaces. This theorem extends, unifies and generalizes several well-known comparable results in the existing literature.

On the other hand, Samet et al. [12] introduced the concept of $\alpha$-admissible mapping and using this concept proved a fixed point theorem for a single-valued mapping. They also showed that these results can be utilized to derive fixed point theorems in partially ordered spaces and coupled fixed point theorems. Moreover, they applied the main results to ordinary differential equations. Recently, Mohammadi et al. [13] introduced the

o2013 Sintunavarat et al: licensee Springer. This is an Open Access article distributed under the terms of the Creative Commons Attribution License (http://creativecommons.org/licenses/by/2.0), which permits unrestricted use, distribution, and reproduction in any medium, provided the original work is properly cited. 
concept of $\alpha$-admissible for a set-valued mapping which is different from the notion of $\alpha_{*}$-admissible which was provided in [14]. Subsequently, there are a number of results via the concept of $\alpha$-admissible mapping in many spaces (see [15-20] and references therein).

Inspired and motivated by Aydi et al. [10] and Mohammadi et al. [13], we introduce the class of $q$-set-valued $\alpha$-quasi-contraction mappings and give a fixed point theorem for such mappings via the idea of $\alpha$-admissible mapping. Our result improves and complements the main result of Aydi et al. [10] and many results in the literature. We also provide some examples to show the generality of our result. The applications for fixed point theorems in a $b$-metric space endowed with an arbitrary binary relation are also derived from our results. Furthermore, at the end of this paper, we give open problems for further investigation.

\section{Auxiliary notions}

Throughout this paper, the standard notations and terminologies in nonlinear analysis are used. For the convenience of the reader, we recall some of them. In the sequel, $\mathbb{R}, \mathbb{R}_{+}$and $\mathbb{N}$ denote the set of real numbers, the set of nonnegative real numbers and the set of positive integers, respectively.

Definition $2.1([1,2])$ Let $X$ be a nonempty set and $s \geq 1$ be a given real number. A functional $d: X \times X \rightarrow \mathbb{R}_{+}$is called a $b$-metric if for all $x, y, z \in X$ the following conditions are satisfied:

(1) $d(x, y)=0$ if and only if $x=y$;

(2) $d(x, y)=d(y, x)$;

(3) $d(x, z) \leq s[d(x, y)+d(y, z)]$.

A pair $(X, d)$ is called a $b$-metric space (with constant $s$ ).

It is easy to see that any metric space is a $b$-metric space with $s=1$. Therefore, the class of $b$-metric spaces is larger than the class of metric spaces.

Some known examples of $b$-metric, which show that a $b$-metric space is real generalization of a metric space, are the following.

Example 2.2 The set of real numbers together with the functional

$$
d(x, y):=|x-y|^{2}
$$

for all $x, y \in \mathbb{R}$ is a $b$-metric space with constant $s=2$. Also, we obtain that $d$ is not a metric on $X$.

Example 2.3 The set $l_{p}(\mathbb{R})$ with $0<p<1$, where $l_{p}(\mathbb{R}):=\left\{\left.\left\{x_{n}\right\} \subseteq \mathbb{R}\left|\sum_{n=1}^{\infty}\right| x_{n}\right|^{p}<\infty\right\}$, together with the functional $d: l_{p}(\mathbb{R}) \times l_{p}(\mathbb{R}) \rightarrow \mathbb{R}$,

$$
d(x, y):=\left(\sum_{n=1}^{\infty}\left|x_{n}-y_{n}\right|^{p}\right)^{\frac{1}{p}}
$$

for each $x=\left\{x_{n}\right\}, y=\left\{y_{n}\right\} \in l_{p}(\mathbb{R})$, is a $b$-metric space with coefficient $s=2^{\frac{1}{p}}>1$. It is obtained that the above result also holds for the general case $l_{p}(X)$ with $0<p<1$, where $X$ is a Banach space. 
Example 2.4 Let $p$ be a given real number in the interval $(0,1)$. The space $L_{p}[0,1]$ of all real functions $x(t), t \in[0,1]$ such that $\int_{0}^{1}|x(t)|^{p} d t<1$, together with the functional

$$
d(x, y):=\left(\int_{0}^{1}|x(t)-y(t)|^{p} d t\right)^{1 / p} \quad \text { for each } x, y \in L_{p}[0,1],
$$

is a $b$-metric space with constant $s=2^{\frac{1}{p}}$.

Example 2.5 Let $X=\{0,1,2\}$ and a functional $d: X \times X \rightarrow \mathbb{R}_{+}$be defined by

$$
\begin{aligned}
& d(0,0)=d(1,1)=d(2,2)=0, \\
& d(0,1)=d(1,0)=d(1,2)=d(2,1)=1
\end{aligned}
$$

and

$$
d(2,0)=d(0,2)=m,
$$

where $m$ is a given real number such that $m \geq 2$. It is easy to see that

$$
d(x, y) \leq \frac{m}{2}[d(x, z)+d(z, y)]
$$

for all $x, y, z \in X$. Therefore, $(X, d)$ is a $b$-metric space with constant $s=m / 2$. However, if $m>2$, the ordinary triangle inequality does not hold and thus $(X, d)$ is not a metric space.

Next, we recall the notions of convergence, compactness, closedness and completeness in a $b$-metric space (see in [5]).

Definition 2.6 ([5]) Let $(X, d)$ be a $b$-metric space. The sequence $\left\{x_{n}\right\}$ in $X$ is called:

(1) convergent if and only if there exists $x \in X$ such that $d\left(x_{n}, x\right) \rightarrow 0$ as $n \rightarrow \infty$. In this case, we write $\lim _{n \rightarrow \infty} d\left(x_{n}, x\right)=0$.

(2) Cauchy if and only if $d\left(x_{n}, x_{m}\right) \rightarrow 0$ as $m, n \rightarrow \infty$.

Remark 2.7 In a $b$-metric space $(X, d)$, the following assertions hold:

(1) a convergent sequence has a unique limit;

(2) each convergent sequence is Cauchy;

(3) in general, a $b$-metric is not continuous.

Definition 2.8 ([5]) Let $Y$ be a nonempty subset of a $b$-metric space $(X, d)$. The closure $\bar{Y}$ of $Y$ is the set of limits of all convergent sequences of points in $Y$, i.e.,

$$
\bar{Y}:=\left\{x \in X: \text { there exists a sequence }\left\{x_{n}\right\} \text { in } X \text { such that } \lim _{n \rightarrow \infty} x_{n}=x\right\} \text {. }
$$

Definition 2.9 ([5]) Let $(X, d)$ be a $b$-metric space. A subset $Y \subseteq X$ is called:

(1) closed if and only if for each sequence $\left\{x_{n}\right\}$ in $Y$, which converges to an element $x$, we have $x \in Y($ i.e., $Y=\bar{Y}$ ); 
(2) compact if and only if for every sequence of element in $Y$ there exists a subsequence that converges to an element in $Y$;

(3) bounded if and only if $\delta(Y):=\sup \{d(a, b) \mid a, b \in Y\}<\infty$.

Definition 2.10 The $b$-metric space $(X, d)$ is complete if every Cauchy sequence in $X$ converges.

Now, we consider the following notations of a collection of subsets of a $b$-metric space $(X, d)$ :

$$
\begin{aligned}
& \mathcal{P}(X):=\{Y \mid Y \subseteq X\} ; \\
& P(X):=\{Y \in \mathcal{P}(X) \mid Y \neq \emptyset\} ; \\
& P_{b}(X):=\{Y \in P(X) \mid Y \text { is bounded }\} ; \\
& P_{c p}(X):=\{Y \in P(X) \mid Y \text { is compact }\} ; \\
& P_{c l}(X):=\{Y \in P(X) \mid Y \text { is closed }\} ; \\
& P_{b, c l}(X):=P_{b}(X) \cap P_{c l}(X) .
\end{aligned}
$$

Here, we give the concept of generalized functionals on a $b$-metric space $(X, d)$.

Definition 2.11 Let $(X, d)$ be a $b$-metric space.

(1) The functional $D: \mathcal{P}(X) \times \mathcal{P}(X) \rightarrow \mathbb{R} \cup\{+\infty\}$ is said to be gap functional if and only if it is defined by

$$
D(A, B)= \begin{cases}\inf \{d(a, b) \mid a \in A, b \in B\}, & A \neq \emptyset \neq B, \\ 0, & A=\emptyset=B, \\ +\infty, & \text { otherwise. }\end{cases}
$$

In particular, if $x_{0} \in X$, then $d\left(x_{0}, B\right):=D\left(\left\{x_{0}\right\}, B\right)$.

(2) The functional $\rho: \mathcal{P}(X) \times \mathcal{P}(X) \rightarrow \mathbb{R} \cup\{+\infty\}$ is said to be excess generalized functional if and only if it is defined by

$$
\rho(A, B)= \begin{cases}\sup \{d(a, B) \mid a \in A\}, & A \neq \emptyset \neq B, \\ 0, & A=\emptyset, \\ +\infty, & \text { otherwise. }\end{cases}
$$

(3) The functional $H: \mathcal{P}(X) \times \mathcal{P}(X) \rightarrow \mathbb{R} \cup\{+\infty\}$ is said to be Pompeiu-Hausdorff generalized functional if and only if it is defined by

$$
H(A, B)= \begin{cases}\max \{\rho(A, B), \rho(B, A)\}, & A \neq \emptyset \neq B, \\ 0, & A=\emptyset, \\ +\infty, & \text { otherwise. }\end{cases}
$$

It is well know (see in [7]) that $\left(P_{c p}(X), H\right)$ is a complete $b$ metric space provided $(X, d)$ is a complete $b$-metric space. 
Remark 2.12 For a $b$-metric space $(X, d)$, we have

$$
d(x, B) \leq \rho(A, B) \leq H(A, B)
$$

for all $A, B \in P(X)$ and $x \in A$. We also obtain that for $B \in P(X)$, we get

$$
d(x, B) \leq d(x, b)
$$

for all $b \in B$.

The following lemmas from Czerwik [7] are useful for some of the proofs in the main result.

Lemma $2.13([7])$ Let $(X, d)$ be a b-metric space. Then

$$
d(x, A) \leq s[d(x, B)+H(B, A)]
$$

for all $x \in X$ and $A, B \in P(X)$. In particular, we have

$$
d(x, A) \leq s[d(x, y)+d(y, A)]
$$

for all $x, y \in X$ and $A \in P(X)$.

Lemma $2.14([7])$ Let $(X, d)$ be a b-metric space. Then

$$
H(A, C) \leq s[H(A, B)+H(B, C)]
$$

for all $A, B, C \in P(X)$.

Lemma 2.15 ([7]) Let $(X, d)$ be a b-metric space and $A, B \in P_{b, c l}(X)$. Then, for each $\epsilon>0$ and for all $b \in B$, there exists $a \in A$ such that $d(a, b) \leq H(A, B)+\epsilon$.

Lemma 2.16 ([7]) Let $(X, d)$ be a b-metric space. For $A \in P_{b, c l}(X)$ and $x \in X$, we have

$$
d(x, A)=0 \quad \Longrightarrow \quad x \in A \text {. }
$$

Lemma 2.17 ([21]) Let $(X, d)$ be a b-metric space (with constant $s \geq 1)$, and let $\left\{x_{n}\right\}$ be a sequence in $X$ such that

$$
d\left(x_{n+1}, x_{n+2}\right) \leq \gamma d\left(x_{n}, x_{n+1}\right)
$$

for all $n \in \mathbb{N}$, where $0 \leq \gamma<1$. Then the sequence $\left\{x_{n}\right\}$ is a Cauchy sequence in $X$ provided that $s \gamma<1$.

Definition 2.18 ([12]) Let $X$ be a nonempty set, $t: X \rightarrow X$ and $\alpha: X \times X \rightarrow[0, \infty)$. We say that $t$ is $\alpha$-admissible if

$$
\text { for } x, y \in X \text { for which } \alpha(x, y) \geq 1 \quad \Longrightarrow \quad \alpha(t x, t y) \geq 1 \text {. }
$$


Definition $2.19([13,14])$ Let $X$ be a nonempty set, $T: X \rightarrow 2^{X}$, where $2^{X}$ is a collection of subsets of $X$ and $\alpha: X \times X \rightarrow[0, \infty)$. We say that

(1) $T$ is $\alpha_{*}$-admissible if

$$
\text { for } x, y \in X \text { for which } \alpha(x, y) \geq 1 \quad \Longrightarrow \quad \alpha_{*}(T x, T y) \geq 1 \text {, }
$$

where $\alpha_{*}(T x, T y):=\inf \{\alpha(a, b) \mid a \in T x, b \in T y\}$.

(2) $T$ is $\alpha$-admissible whenever for each $x \in X$ and $y \in T x$ with $\alpha(x, y) \geq 1$, we have $\alpha(y, z) \geq 1$ for all $z \in T y$.

Remark 2.20 It is easy to prove that the set-valued mapping $T$ is $\alpha_{*}$-admissible implies that $T$ is $\alpha$-admissible mapping.

\section{The existence of fixed point theorems for a set-valued mapping in b-metric spaces}

In this section, we introduce the $q$-set-valued $\alpha$-quasi-contraction mapping and obtain the existence of a fixed point theorem for such a mapping in $b$-metric spaces.

Definition 3.1 Let $(X, d)$ be a $b$-metric space and $\alpha: X \times X \rightarrow[0, \infty)$ be a mapping. The set-valued mapping $T: X \rightarrow P_{b, c l}(X)$ is said to be a $q$-set-valued $\alpha$-quasi-contraction if

$$
\alpha(x, y) H(T x, T y) \leq q M(x, y)
$$

for all $x, y \in X$, where $0 \leq q<1$ and

$$
M(x, y)=\max \{d(x, y), d(x, T x), d(y, T y), d(x, T y), d(y, T x)\} .
$$

Next, we give the main result in this paper.

Theorem 3.2 Let $(X, d)$ be a complete $b$-metric space (with constant $s \geq 1$ ) such that the $b$-metric is a continuous functional on $X \times X$, let $\alpha: X \times X \rightarrow[0, \infty)$ be a mapping, and let $T: X \rightarrow P_{b, c l}(X)$ be a q-set-valued $\alpha$-quasi-contraction. Suppose that the following conditions hold:

(i) $T$ is $\alpha$-admissible;

(ii) there exist $x_{0} \in X$ and $x_{1} \in T x_{0}$ such that $\alpha\left(x_{0}, x_{1}\right) \geq 1$;

(iii) if $\left\{x_{n}\right\}$ is a sequence in $X$ such that $\alpha\left(x_{n}, x_{n+1}\right) \geq 1$ for all $n \in \mathbb{N}$ and $x_{n} \rightarrow x$ as $n \rightarrow \infty$ for some $x \in X$, then $\alpha\left(x_{n}, x\right) \geq 1$.

If we set $q<\frac{1}{s^{2}+s}$, then $T$ has a fixed point in $X$, that is, there exists $u \in X$ such that $u \in T u$.

Proof We obtain that $M(x, y)=0$ if and only if $x=y$ is a fixed point of $T$. Therefore, we suppose that $M(x, y)>0$ for all $x, y \in X$.

Next, we set

$$
\varepsilon:=\frac{1}{2}\left(\frac{1}{s^{2}+s}-q\right) \text { and } \beta:=q+\varepsilon=\frac{1}{2}\left(\frac{1}{s^{2}+s}+q\right) .
$$

Since $q<\frac{1}{s^{2}+s}$, we obtain that $\varepsilon>0$ and $0<\beta<\frac{1}{s^{2}+s}$. 
Starting from (ii), we can choose $x_{0} \in X$ and $x_{1} \in T x_{0}$ such that $\alpha\left(x_{0}, x_{1}\right) \geq 1$. By Lemma 2.15, there exists $x_{2} \in T x_{1}$ such that

$$
\begin{aligned}
d\left(x_{1}, x_{2}\right) & \leq H\left(T x_{0}, T x_{1}\right)+\varepsilon M\left(x_{0}, x_{1}\right) \\
& \leq \alpha\left(x_{0}, x_{1}\right) H\left(T x_{0}, T x_{1}\right)+\varepsilon M\left(x_{0}, x_{1}\right) \\
& \leq q M\left(x_{0}, x_{1}\right)+\varepsilon M\left(x_{0}, x_{1}\right) \\
& =\beta M\left(x_{0}, x_{1}\right) .
\end{aligned}
$$

Since $x_{0} \in X$ and $x_{1} \in T x_{0}$ such that $\alpha\left(x_{0}, x_{1}\right) \geq 1$ and from $T$ is $\alpha$-admissible, we have $\alpha\left(x_{1}, x_{2}\right) \geq 1$. Using Lemma 2.15 , there exists $x_{3} \in T x_{2}$ such that

$$
\begin{aligned}
d\left(x_{2}, x_{3}\right) & \leq H\left(T x_{1}, T x_{2}\right)+\varepsilon M\left(x_{1}, x_{2}\right) \\
& \leq \alpha\left(x_{1}, x_{2}\right) H\left(T x_{1}, T x_{2}\right)+\varepsilon M\left(x_{1}, x_{2}\right) \\
& \leq q M\left(x_{1}, x_{2}\right)+\varepsilon M\left(x_{1}, x_{2}\right) \\
& =\beta M\left(x_{1}, x_{2}\right) .
\end{aligned}
$$

By induction, we can construct a sequence $\left\{x_{n}\right\}$ in $X$ such that, for each $n \in \mathbb{N}$, we have

$$
x_{n} \in T x_{n-1}, \quad \alpha\left(x_{n-1}, x_{n}\right) \geq 1
$$

and

$$
d\left(x_{n}, x_{n+1}\right) \leq \beta M\left(x_{n-1}, x_{n}\right) .
$$

Assume that $x_{\widehat{n}-1}=x_{\widehat{n}}$ for some $\widehat{n} \in \mathbb{N}$, then we have $x_{\widehat{n}} \in T x_{\widehat{n}}$, so the proof is completed. For the rest, assume that for each $n \in \mathbb{N}, d\left(x_{n-1}, x_{n}\right)>0$.

For each $n \in \mathbb{N}$, we get

$$
\begin{aligned}
d\left(x_{n}, x_{n+1}\right) & \leq \beta M\left(x_{n-1}, x_{n}\right) \\
& =\beta \max \left\{d\left(x_{n-1}, x_{n}\right), d\left(x_{n-1}, T x_{n-1}\right), d\left(x_{n}, T x_{n}\right), d\left(x_{n-1}, T x_{n}\right), d\left(x_{n}, T x_{n-1}\right)\right\} \\
& \leq \beta \max \left\{d\left(x_{n-1}, x_{n}\right), d\left(x_{n-1}, x_{n}\right), d\left(x_{n}, x_{n+1}\right), d\left(x_{n-1}, x_{n+1}\right), d\left(x_{n}, x_{n}\right)\right\} \\
& \leq \beta \max \left\{d\left(x_{n-1}, x_{n}\right), d\left(x_{n}, x_{n+1}\right), s\left[d\left(x_{n-1}, x_{n}\right)+d\left(x_{n}, x_{n+1}\right)\right]\right\} \\
& \leq \beta s\left[d\left(x_{n-1}, x_{n}\right)+d\left(x_{n}, x_{n+1}\right)\right] .
\end{aligned}
$$

This implies that

$$
d\left(x_{n}, x_{n+1}\right) \leq \gamma d\left(x_{n-1}, x_{n}\right)
$$

for all $n \in \mathbb{N}$, where $\gamma:=\frac{\beta s}{1-\beta s}$.

Since $s \geq 1, \beta=\frac{1}{2}\left(\frac{1}{s^{2}+s}+q\right)$ and $q<\frac{1}{s^{2}+s}$, we have 
By (3.3), (3.4) and Lemma 2.17, the sequence $\left\{x_{n}\right\}$ is Cauchy in $(X, d)$. It follows from the completeness of $X$ that there exists $u \in X$ such that

$$
\lim _{n \rightarrow \infty} x_{n}=u
$$

Next, we show that $u \in T u$. By condition (iii), we have $\alpha\left(x_{n}, u\right) \geq 1$. From Lemma 2.13 and (3.1), for $n \in \mathbb{N}$, we have

$$
\begin{aligned}
d(u, T u) \leq & s\left[d\left(u, x_{n+1}\right)+d\left(x_{n+1}, T u\right)\right] \\
\leq & s\left[d\left(u, x_{n+1}\right)+H\left(T x_{n}, T u\right)\right] \\
\leq & s\left[d\left(u, x_{n+1}\right)+\alpha\left(x_{n}, u\right) H\left(T x_{n}, T u\right)\right] \\
\leq & s\left[d\left(u, x_{n+1}\right)+q M\left(x_{n}, u\right)\right] \\
= & s\left[d\left(u, x_{n+1}\right)+q \max \left\{d\left(x_{n}, u\right), d\left(x_{n}, T x_{n}\right), d(u, T u), d\left(x_{n}, T u\right), d\left(u, T x_{n}\right)\right\}\right] \\
\leq & s\left[d\left(u, x_{n+1}\right)+q \max \left\{d\left(x_{n}, u\right), d\left(x_{n}, x_{n+1}\right), d(u, T u), d\left(x_{n}, T u\right), d\left(u, x_{n+1}\right)\right\}\right] \\
\leq & s\left[d\left(u, x_{n+1}\right)+q \max \left\{d\left(x_{n}, u\right), s\left[d\left(x_{n}, u\right)+d\left(u, x_{n+1}\right)\right], d(u, T u),\right.\right. \\
& \left.\left.s\left[d\left(x_{n}, u\right)+d(u, T u)\right], d\left(u, x_{n+1}\right)\right\}\right] .
\end{aligned}
$$

Letting $n \rightarrow \infty$ in the above inequality, we get

$$
d(u, T u) \leq q s^{2} d(u, T u)
$$

Since $q<\frac{1}{s^{2}+s}$, we get $q s^{2}<1$. From (3.6), we have $d(u, T u)=0$. By Lemma 2.16, we get $u \in T u$, that is, $u$ is a fixed point of $T$. This completes the proof.

Theorem 3.3 Let $(X, d)$ be a complete b-metric space (with constant $s \geq 1$ ) such that the $b$-metric is a continuous functional on $X \times X$, let $\alpha: X \times X \rightarrow[0, \infty)$ be a mapping, and let $T: X \rightarrow P_{b, c l}(X)$ be a q-set-valued $\alpha$-quasi-contraction. Suppose that the following conditions hold:

(i) $T$ is $\alpha_{*}$-admissible;

(ii) there exist $x_{0} \in X$ and $x_{1} \in T x_{0}$ such that $\alpha\left(x_{0}, x_{1}\right) \geq 1$;

(iii) if $\left\{x_{n}\right\}$ is a sequence in $X$ such that $\alpha\left(x_{n}, x_{n+1}\right) \geq 1$ for all $n \in \mathbb{N}$ and $x_{n} \rightarrow x$ as $n \rightarrow \infty$ for some $x \in X$, then $\alpha\left(x_{n}, x\right) \geq 1$.

If we set $q<\frac{1}{s^{2}+s}$, then $T$ has a fixed point in $X$, that is, there exists $u \in X$ such that $u \in T u$.

Proof We can prove this result by using Theorem 3.2 and Remark 2.20 .

Corollary 3.4 (Theorem 2.2 in [10]) Let $(X, d)$ be a complete b-metric space (with constant $s \geq 1$ ) such that the $b$-metric is a continuous functional on $X \times X$, and let $T: X \rightarrow P_{b, c l}(X)$ be a q-set-valued quasi-contraction. If we set $q<\frac{1}{s^{2}+s}$, then $T$ has a fixed point in $X$, that is, there exists $u \in X$ such that $u \in T u$.

Proof Setting $\alpha(x, y)=1$ for all $x, y \in X$. By Theorem 3.2 (or Theorem 3.3), we obtain the desired result. 
Remark 3.5 The condition of $q$ in Theorem 3.2 becomes $q<\frac{1}{2}$ if we take $s=1$ (it corresponds to the case of metric spaces). Therefore, Theorems 3.2 and 3.3 are generalization of many known results in metric spaces.

Remark 3.6 Theorem 3.2 is an extension of Theorem 2.2 of Aydi et al. [10], which itself extends and improves the results of Amini-Harandi [11], Daffer and Kaneko [22], Rouhani and Moradi [23] and Singh et al. [21].

The following example shows that Theorem 3.2 properly generalizes the main result, Theorem 2.2, of Aydi et al. [10].

Example 3.7 Let $X=\mathbb{R}$ with the functional $d: X \times X \rightarrow \mathbb{R}_{+}$be defined by $d(x, y):=\mid x-$ $\left.y\right|^{2}$. Clearly, $(X, d)$ is a complete $b$-metric space with constant $s=2$. Define the set-valued mapping $T: X \rightarrow P_{b, c l}(X)$ by

$$
T x= \begin{cases}{[x, \max \{x, 5\}],} & x>1, \\ {\left[0, \frac{x}{4}\right],} & 0 \leq x \leq 1, \\ {[\min \{x,-5\}, x],} & x<0,\end{cases}
$$

and $\alpha: X \times X \rightarrow[0, \infty)$ by

$$
\alpha(x, y)= \begin{cases}1, & x, y \in[0,1] \\ 0, & \text { otherwise }\end{cases}
$$

We obtain that $H(T 0, T 4)=16$ and $M(0,4)=16$. Therefore,

$$
H(T 0, T 4)>q M(0,4)
$$

for all $0 \leq q<1$. This implies that the contraction condition of Theorem 2.2 of Aydi et al. [10] is not true for this case. Therefore, Theorem 2.2 cannot be used to claim the existence of a fixed point of $T$.

Next, we show that our result can be applied to this case. First of all, we show that $T$ is a $q$-set-valued $\alpha$-quasi-contraction mapping, where $q=\frac{1}{16}$. We need only to show the case of $x, y \in[0,1]$ since the other case is trivial. For $x, y \in[0,1]$, we have

$$
\begin{aligned}
\alpha(x, y) H(T x, T y) & =\left|\frac{x}{4}-\frac{y}{4}\right|^{2} \\
& =\frac{|x-y|^{2}}{16} \\
& =q d(x, y) \\
& \leq q M(x, y) .
\end{aligned}
$$

This shows that $T$ is a $q$-set-valued $\alpha$-quasi-contraction mapping. Also, we have

$$
q=\frac{1}{16}<\frac{1}{6}=\frac{1}{s^{2}+s} .
$$


It is easy to check that $T$ is an $\alpha$-admissible mapping. For $x_{0}=1$ and $x_{1}=0 \in T x_{0}$, we have $\alpha\left(x_{0}, x_{1}\right) \geq 1$. Further, for any sequence $\left\{x_{n}\right\}$ in $X$ with $x_{n} \rightarrow x$ as $n \rightarrow \infty$ for some $x \in X$ and $\alpha\left(x_{n}, x_{n+1}\right) \geq 1$ for all $n \in \mathbb{N}$, we obtain that $\alpha\left(x_{n}, x\right) \geq 1$ for all $n \in \mathbb{N}$.

Therefore, all hypotheses of Theorem 3.2 are satisfied, and so $T$ has infinitely many fixed points.

Next, we give the result for a single-valued mapping which is an extension of Corollary 2.4 of Aydi et al. [10] and the result of Ćirić [24].

Corollary 3.8 Let $(X, d)$ be a complete $b$-metric space (with constant $s \geq 1$ ) such that the $b$-metric is a continuous functional on $X \times X$, let $\alpha: X \times X \rightarrow[0, \infty)$ be a mapping, and let $t: X \rightarrow X$ be a q-single-valued $\alpha$-quasi-contraction, that is,

$$
\alpha(x, y) d(t x, t y) \leq q m(x, y)
$$

for all $x, y \in X$, where $0 \leq q<1$ and

$$
m(x, y)=\max \{d(x, y), d(x, t x), d(y, t y), d(x, t y), d(y, t x)\} .
$$

Suppose that the following conditions hold:

(i) $t$ is $\alpha$-admissible;

(ii) there exists $x_{0} \in X$ such that $\alpha\left(x_{0}, t x_{0}\right) \geq 1$;

(iii) if $\left\{x_{n}\right\}$ is a sequence in $X$ such that $\alpha\left(x_{n}, x_{n+1}\right) \geq 1$ for all $n \in \mathbb{N}$ and $x_{n} \rightarrow x$ as $n \rightarrow \infty$ for some $x \in X$, then $\alpha\left(x_{n}, x\right) \geq 1$.

If we set $q<\frac{1}{s^{2}+s}$, then $t$ has a fixed point in $X$, that is, there exists $u \in X$ such that $u=t u$.

Proof It follows by applying Theorem 3.2 or 3.3.

\section{Applications on a $b$-metric space endowed with an arbitrary binary relation}

In this section, we give the existence of fixed point theorems on a $b$-metric space endowed with an arbitrary binary relation.

Before presenting our results, we give the following definitions.

Definition 4.1 Let $(X, d)$ be a $b$-metric space and $\mathcal{R}$ be a binary relation over $X$. We say that $T: X \rightarrow P_{b, c l}(X)$ is a preserving mapping if for each $x \in X$ and $y \in T x$ with $x \mathcal{R} y$, we have $y \mathcal{R} z$ for all $z \in T y$.

Definition 4.2 Let $(X, d)$ be a $b$-metric space and $\mathcal{R}$ be a binary relation over $X$. The set-valued mapping $T: X \rightarrow P_{b, c l}(X)$ is said to be a $q$-set-valued quasi-contraction with respect to $\mathcal{R}$ if

$$
H(T x, T y) \leq q M(x, y)
$$

for all $x, y \in X$ for which $x \mathcal{R} y$, where $0 \leq q<1$ and

$$
M(x, y)=\max \{d(x, y), d(x, T x), d(y, T y), d(x, T y), d(y, T x)\} .
$$


Theorem 4.3 Let $(X, d)$ be a complete $b$-metric space (with constant $s \geq 1$ ) such that the $b$-metric is a continuous functional on $X \times X, \mathcal{R}$ be a binary relation over $X$ and $T: X \rightarrow$ $P_{b, c l}(X)$ be a $q$-set-valued quasi-contraction with respect to $\mathcal{R}$. Suppose that the following conditions hold:

(i) $T$ is a preserving mapping;

(ii) there exist $x_{0} \in X$ and $x_{1} \in T x_{0}$ such that $x_{0} \mathcal{R} x_{1}$;

(iii) if $\left\{x_{n}\right\}$ is a sequence in $X$ such that $x_{n} \mathcal{R} x_{n+1}$ for all $n \in \mathbb{N}$ and $x_{n} \rightarrow x$ as $n \rightarrow \infty$ for some $x \in X$, then $x_{n} \mathcal{R} x$.

If we set $q<\frac{1}{s^{2}+s}$, then $T$ has a fixed point in $X$, that is, there exists $u \in X$ such that $u \in T u$.

Proof Consider the mapping $\alpha: X \times X \rightarrow[0, \infty)$ defined by

$$
\alpha(x, y)= \begin{cases}1 & \text { if } x \mathcal{R} y \\ 0 & \text { otherwise }\end{cases}
$$

From condition (ii), we get $\alpha\left(x_{0}, x_{1}\right) \geq 1$. It follows from $T$ is a preserving mapping that $T$ is an $\alpha$-admissible mapping. Since $T$ is a $q$-set-valued quasi-contraction with respect to $\mathcal{R}$, we have, for all $x, y \in X$,

$$
\alpha(x, y) H(T x, T y) \leq q M(x, y) .
$$

This implies that $T$ is a $q$-set-valued $\alpha$-quasi-contraction mapping. Now all the hypotheses of Theorem 3.2 are satisfied and so the existence of the fixed point of $T$ follows from Theorem 3.2.

Next, we give some special case of Theorem 4.3 in partially ordered $b$-metric spaces. Before studying next results, we give the following definitions.

Definition 4.4 Let $X$ be a nonempty set. Then $(X, d, \preceq)$ is called a partially ordered $b$ metric space if $(X, d)$ is a $b$-metric space and $(X, \preceq)$ is a partially ordered space.

Definition 4.5 Let $(X, d, \preceq)$ be a partially ordered $b$-metric space. We say that $T: X \rightarrow$ $P_{b, c l}(X)$ is a preserving mapping with $\preceq$ if for each $x \in X$ and $y \in T x$ with $x \preceq y$, we have $y \preceq z$ for all $z \in T y$.

Definition 4.6 Let $(X, d, \preceq)$ be a partially ordered $b$-metric space. The set-valued mapping $T: X \rightarrow P_{b, c l}(X)$ is said to be a $q$-set-valued quasi-contraction with respect to $\preceq$ if

$$
H(T x, T y) \leq q M(x, y)
$$

for all $x, y \in X$ for which $x \preceq y$, where $0 \leq q<1$ and

$$
M(x, y)=\max \{d(x, y), d(x, T x), d(y, T y), d(x, T y), d(y, T x)\} .
$$

Corollary 4.7 Let $(X, d, \preceq)$ be a complete partially ordered b-metric space (with constant $s \geq 1)$ such that the $b$-metric is a continuous functional on $X \times X$ and $T: X \rightarrow P_{b, c l}(X)$ be a $q$-set-valued quasi-contraction with respect to $\preceq$. Suppose that the following conditions hold: 
(i) $T$ is a preserving mapping with $\preceq$;

(ii) there exist $x_{0} \in X$ and $x_{1} \in T x_{0}$ such that $x_{0} \preceq x_{1}$;

(iii) if $\left\{x_{n}\right\}$ is a sequence in $X$ such that $x_{n} \preceq x_{n+1}$ for all $n \in \mathbb{N}$ and $x_{n} \rightarrow x$ as $n \rightarrow \infty$ for some $x \in X$, then $x_{n} \preceq x$.

If we set $q<\frac{1}{s^{2}+s}$, then $T$ has a fixed point in $X$, that is, there exists $u \in X$ such that $u \in T u$.

Proof The result follows from Theorem 4.3 by considering the binary relation $\preceq$.

Open question 1 In Theorems 3.2 and 3.3, can we find the sufficient condition to prove the uniqueness of a fixed point for a set-valued mapping?

Open question 2 Is the fixed point problem for a $q$-set-valued $\alpha$-contraction mapping well posed?

\section{Competing interests}

The authors declare that they have no competing interests.

\section{Authors' contributions}

All authors contributed equally and significantly in writing this paper. All authors read and approved the final manuscript.

\section{Author details}

${ }^{1}$ Department of Mathematics and Statistics, Faculty of Science and Technology, Thammasat University Rangsit Center, Pathumthani, 12121, Thailand. ${ }^{2}$ Department of Mathematics, Faculty of Science, Naresuan University, Phitsanulok, 65000, Thailand. ${ }^{3}$ Division of Mathematics, Faculty of Science and Agricultural Technology, Rajamangala University of Technology Lanna Tak, Tak, 63000, Thailand.

\section{Acknowledgements}

This research was supported by the Commission on Higher Education, the Thailand Research Fund and the Rajamangala University of Technology Lanna Tak (Grant No. MRG5580233).

\section{Received: 7 June 2013 Accepted: 1 October 2013 Published: 11 Nov 2013}

\section{References}

1. Bakhtin, IA: The contraction mapping principle in quasimetric spaces. Funct. Anal., Unianowsk Gos. Ped. Inst. 30, 26-37 (1989)

2. Czerwik, S: Contraction mappings in b-metric spaces. Acta Math. Inform. Univ. Ostrav. 1, 5-11 (1993)

3. Abusalim, SM, Md Noorani, MS: Fixed point and common fixed point theorems on ordered cone $b$-metric spaces. Abstr. Appl. Anal. 2013, Article ID 815289 (2013)

4. Boriceanu, M: Fixed point theory for multivalued generalized contraction on a set with two $b$-metrics. Stud. Univ. Babeş-Bolyai, Math. LIV(3), 3-14 (2009)

5. Boriceanu, M, Bota, M, Petrusel, A: Multivalued fractals in b-metric spaces. Cent. Eur. J. Math. 8(2), 367-377 (2010)

6. Czerwik, S, Dlutek, K, Singh, SL: Round-off stability of iteration procedures for operators in b-metric spaces. J. Natur. Phys. Sci. 11, 87-94 (1997)

7. Czerwik, S: Nonlinear set-valued contraction mappings in b-metric spaces. Atti Semin. Mat. Fis. Univ. Modena 46(2), 263-276 (1998)

8. Hussain, N, Shah, MH, Harandi, AA, Akhtar, Z: Common fixed point theorems for generalized contractive mappings with applications. Fixed Point Theory Appl. 2013, 169 (2013)

9. Parvaneh, V, Roshan, JR, Radenovic, S: Existence of tripled coincidence point in ordered $b$-metric spaces and application to a system of integral equations. Fixed Point Theory Appl. 2013, 130 (2013)

10. Aydi, H, Bota, M-F, Karapinar, E, Mitrović, S: A fixed point theorem for set-valued quasicontractions in $b$-metric spaces. Fixed Point Theory Appl. 2012, 88 (2012)

11. Amini-Harandi, A: Fixed point theory for set-valued quasi-contraction maps in metric spaces. Appl. Math. Lett. 24(11), 1791-1794 (2011)

12. Samet, B, Vetro, C, Vetro, P: Fixed point theorems for $\alpha$ - $\psi$-contractive type mappings. Nonlinear Anal. 75, 2154-2165 (2012)

13. Mohammadi, B, Rezapour, S, Shahzad, N: Some results on fixed points of $\alpha$ - $\psi$-Ciric generalized multifunctions. Fixed Point Theory Appl. 2013, 24 (2013)

14. Asl, JH, Rezapour, S, Shahzad, N: On fixed points of $\alpha$ - $\psi$-contractive multifunctions. Fixed Point Theory Appl. 2012, $212(2012)$

15. Agarwal, RP, Sintunavarat, W, Kumam, P: PPF dependent fixed point theorems for an $\alpha_{c}$-admissible non-self mapping in the Razumikhin class. Fixed Point Theory Appl. (to appear)

16. Alghamdi, MA, Karapinar, E: G- $\beta-\psi$ contractive type mappings and related fixed point theorems. J. Inequal. Appl. 2013, $70(2013)$ 
17. Hussain, N, Karapinar, E, Salimi, P, Vetro, P: Fixed point results for $G^{m}$-Meir-Keeler contractive and $G$ - $(\alpha, \psi)$-Meir-Keeler contractive mappings. Fixed Point Theory Appl. 2013, 34 (2013)

18. Kutbi, MA, Sintunavarat, W: The existence of fixed point theorems via $w$-distance and $\alpha$-admissible mappings and applications. Abstr. Appl. Anal. 2013, Article ID 165434 (2013)

19. Hussain, N, Salimi, P, Latif, A: Fixed point results for single and set-valued $\alpha-\eta$ - $\psi$-contractive mappings. Fixed Point Theory Appl. 2013, 212 (2013)

20. Salimi, P, Latif, A, Hussain, N: Modified $\alpha$ - $\psi$-contractive mappings with applications. Fixed Point Theory Appl. 2013, $151(2013)$

21. Singh, SL, Czerwik, S, Krol, K, Singh, A: Coincidences and fixed points of hybrid contractions. Tamsui Oxford Univ. J. Math. Sci. 24(4), 401-416 (2008)

22. Daffer, PZ, Kaneko, H: Fixed points of generalized contractive multi-valued mappings. J. Math. Anal. Appl. 192 655-666 (1995)

23. Djafari Rouhani, B, Moradi, S: Common fixed point of multivalued generalized $(\psi, \phi)$-weak contractive mappings. Fixed Point Theory Appl. 2010, Article ID 708984 (2010)

24. Ćirić, LB: A generalization of Banach's contraction principle. Proc. Am. Math. Soc. 45, 267-273 (1974)

10.1186/1687-1812-2013-296

Cite this article as: Sintunavarat et al.: Fixed point result and applications on a $b$-metric space endowed with an arbitrary binary relation. Fixed Point Theory and Applications 2013, 2013:296

\section{Submit your manuscript to a SpringerOpen ${ }^{\circ}$ journal and benefit from:}

- Convenient online submission

- Rigorous peer review

- Immediate publication on acceptance

Open access: articles freely available online

- High visibility within the field

- Retaining the copyright to your article 